\title{
VARIATIONS IN PHYTOCONSTITUENTS AND ANTIMICROBIAL ACTIVITIES IN ECOTYPES OF OXALIS CORNICULATA L. AND OXALIS DEBILIS KUNTH
}

\author{
ELEENA PANDA, CHINMAY PRADHAN*, ANATH BANDHU DAS \\ P. G. Department of Botany, Utkal University, Vani Vihar, Bhubaneswar 751004, Odisha, India \\ Email: chinmay.uubot@gmail.com
}

Received: 13 Jul 2016 Revised and Accepted: 23 Aug 2016

\begin{abstract}
Objective: The present study aims at the comparative analysis of phytoconstituents and antimicrobial activities of four ecotypes of Odisha, India, each of Oxalis corniculata L. (OC-Eco-1, OC-Eco-2, OC-Eco-3, OC-Eco-4) and Oxalis debilis Kunth. (OD-Eco-1, OD-Eco-2, OD-Eco-3, OD-Eco-4) of the family Oxalidaceae.

Methods: The ecotypes were collected from four districts (Balasore, Bhadrak, Jajpur, Khurda) of Odisha, India. The qualitative phytochemical screening was done to test glycosides, saponins, tannins and terpenoids. Further analysis of phytochemicals was also screened through TLC and HPTLC. Antimicrobial potentiality of leaf extract of various ecotypes was studied against Bacillus subtilis, Pseudomonas aeruginosa and Streptococcus epidermis by disc diffusion method.

Results: Tannin and terpenoids estimation revealed that significantly high amount of phytoconstituents were present in OD-Eco-3 of 0 . debilis. The methanolic leaf extracts of each ecotype were screened for qualitative analysis of phytochemical through TLC and HPTLC that showed maximum 16 compounds in 0 . debilis (OD-Eco-3) a new report, as compared to 0 . corniculata. All the four ecotypes of 0 . debilis showed some new HPTLC bands (Rf $0.96,0.90,0.90,0.81$ ) as compared to 0 . corniculata that occupied $7.70 \%, 22.38 \%, 23.79 \%$ and $34.42 \%$ of peak area respectively. Cluster analysis on the basis of HPTLC banding pattern showed a close affinity among ecotypes of each species. Crude extracts showed antibacterial activity against B. subtilis, P. aeruginosa and S. epidermis. Leaf extracts of ecotypes of $O$. corniculata showed zones of inhibition and MIC better than that of $O$. debilis against $S$. epidermis.
\end{abstract}

Conclusion: The findings significantly reported some new compounds for the first time in 0 . debilis. The study also indicated a promising potential of antimicrobial activity of $O$. debilis which was the first report.

Keywords: Antimicrobial activity, Genetic diversity, HPTLC, Oxalis, Phytochemical screening

(C) 2016 The Authors. Published by Innovare Academic Sciences Pvt Ltd. This is an open access article under the CC BY license (http://creativecommons.org/licenses/by/4. 0/) DOI: http://dx.doi.org/10.22159/ijpps.2016v8i10.14069

\section{INTRODUCTION}

The therapeutic agents in plant and animal kingdom were very useful for people to confront with illness in early age [1]. The plants with medicinal values and antimicrobial properties were in common use as a therapeutic agent to combat the detrimental side effects of conventional antibiotics as they have wide biological and medicinal activities, higher safety margins, and easy reach to common people with affordable cost [2-4]. The family Oxalidaceae includes eight genera of herbaceous plants, shrubs and small trees with the most predominant genus Oxalis commonly known as 'wood sorrels' [5]. Members of the family show sleeping movements of leaves with glossy and contractile long deep tap roots. Seed dispersal mechanism of Oxalis is well defined through seed pods. The medicinal value of herbs and their extracts were known to cure human ailments since ancient times [6]. Plants were used as therapeutic agents against conventional antibiotics with minimal side effects to treat diseases $[7,8]$. Recently efforts are being taken to isolate and identify the biologically active compounds from the plant extracts. Oxalis corniculata is a natural weed which is extensively used for the cure of dysentery and diarrhoea in India. A wide range of phytochemical constituents (fatty acids, flavonoids, glycoglycerolipid, glycosides, phenol, phytosterols, tannins, and volatile oil) was reported from the plant [5]. Leaves contain fatty acids (linoleic, linolenic, oleic, palmitic acid, and stearic acids), flavonoids, isovitexine, and vitexine-2-0- $\beta$-D-glucopyrunoside. Antioxidant, anticancer, anti-inflammatory, analgesic, antimicrobial, antiamoebic, antifungal, astringent, cardio relaxan, depurative, diuretic, febrifuge, stero-idogenic, stomachic and styptic were reported [6].

Oxalis debilis abundantly present in the Brahmaputra valley region of India [9]. It is used for the treatment of diarrhea. However, there is no report till date on antimicrobial activity of
O. debilis. It is a tristylous species native to Southern America and is a member of the bulb-forming weed and distributed widely throughout the world [10]. The numerical variation in the chromosome (pentaploidy) of African O. debilis was reported [11]. The plant is propagated through vegetative methods as well as by seed dispersal mechanism. There are possibilities of different cytotypes of $O$. debilis which need to be explored and may be one of cause for variation in phytochemical constituents. The medicinal value of $O$. debilis has not yet been extensively studied and needs much more attention for exploration.

The unexplored therapeutic uses of bioactive compounds from $O$. debilis leaf extracts may reveal a great potential of the plant in pharmaceutical science. Therefore, it is imperative to intensify investigations aiming at evaluation of its potentiality against different pathogens. The present study determines the comparative phytochemical and antimicrobial analysis of different ecotypes of $O$. corniculata and $O$. debilis against human pathogens (Bacillus subtilis, Pseudomonas aeruginosa and Streptococcus epidermis). Hence, an attempt has been made to study the antibacterial activity of $O$. debilis. The study also signified the importance of $O$. debilis, as it was the first report on this plant on antimicrobial activity.

\section{MATERIALS AND METHODS}

\section{Phytochemical extraction}

The leaves of four ecotypes each of Oxalis corniculata L. (OC-Eco-1, OC-Eco-2, OC-Eco-3 and OC-Eco-4) and Oxalis debilis Kunth. (ODEco-1, OD-Eco-2, OD-Eco-3 and OD-Eco-4) were collected from different districts of Odisha (fig. 1-2). 


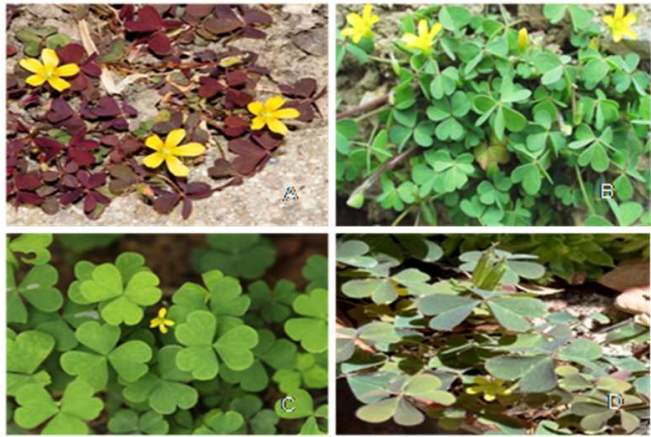

Fig. 1: Morphological characteristics of different ecotypes of $O$. corniculata. A): OC-Eco-1, B): OC-Eco-2, C): OC-Eco-3 and D): OCEco-4. OC= O. corniculata

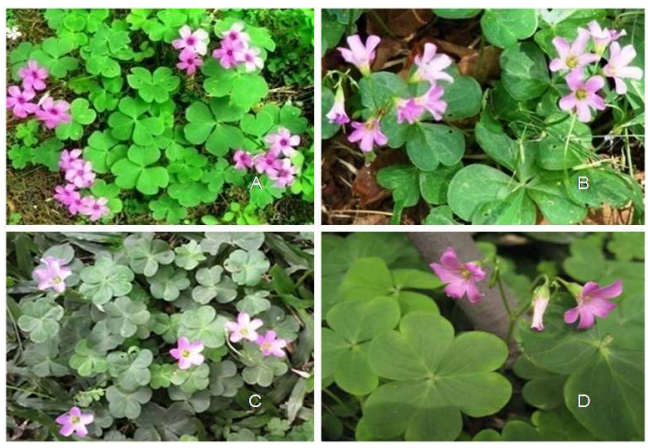

Fig. 2: Morphological characteristics of different ecotypes of $O$. debilis. A): OD-Eco-1, B): OD-Eco-2, C): OD-Eco-3 and D): OD-Eco4. $\mathrm{OD}=0$. debilis

Ecotype-1,-2,-3,-4 were collected from Balasore (Soro), Bhadrak (Bantha chhak), Jajpur (Panikoili) and Khurda (Bhubaneswar) respectively and identified with the help of family keys [12]. Herbariums were prepared for all the collected plant materials and kept in the departmental herbarium, P. G Department of Botany, Utkal University. Leaves were dried in shade for 3-4 $\mathrm{d}$ and homogenized to make powder by using a blender for 5-10 min. The coarse powder stored in eight different air tight jars for the experimental purpose. Leaf powder of each ecotype (75g) was soxhleted with methanol at $40-50^{\circ} \mathrm{C}$ for $18 \mathrm{~h}$. All the extracts of different ecotypes were examined for phytoconstituent analysis and further screened for antimicrobial activities against, Bacillus subtilis (MTCC 441), Pseudomonas aeruginosa (MTCC 3322) and Streptococcus epidermis (MTCC 2453) obtained from IMTECH, Chandigarh, India.

\section{Chemicals and reagents}

Methanol (Merck, India) was used as a solvent for extraction of phytoconstituents of both the plant ecotypes. Chemicals and reagents like benzene, chloroform used in this experiment were procured from Himedia, India and ammonia, iodine, ethanol, sulphuric acid, petroleum ether was obtained from Merck, India for different phytochemical screening. Di-methyl-sulfoxide (Merck, India) was used for antimicrobial activity assay.

\section{Screening of glycoside, saponin, tannin and terpenoids}

Phytochemical screening was carried out for glycosides [13], saponin [14] tannin and terpenoids [15].

\section{TLC analysis}

The extracts were tested on pre-coated Silica Gel G 60 plates (Merck, Germany) for TLC analysis after activation of $15 \mathrm{~min}$ at $100^{\circ} \mathrm{C}$. The solvent system (in $\mathrm{ml}$ ) used was benzene: ammonia: ethanol (18:0.2:2). Developing of TLC plate was made with iodine vapor.

\section{HPTLC analysis}

The extracts were dissolved in the methanol and $10 \mu$ samples were applied in pre-coated TLC plate with the help of Linomat V applicator. The solvent system optimized for HPTLC study was in accordance with the methodology of TLC analysis. The stationary phase was pre-coated, silica gel G 60 F254 (Merck, Germany) plate $(10 \times 10 \mathrm{~cm})$. The plate was developed in twin trough glass chamber using mobile phase (benzene: ammonia: ethanol; 18:0.2:2) (in ml) with ascending separation technique at temperature $20 \pm 5{ }^{\circ} \mathrm{C}$. Visualization of bands and photographs were taken in Camag Linomat V. Each band of the different samples was scanned in UV light (254 $\mathrm{nm}$ and $366 \mathrm{~nm}$ ) on absorbance/reflectance mode using TLC scanner (Camag TLC scanner-3).

\section{UPGMA analysis}

Statistical analysis for HPTLC bands was scored; the presence or absence of the bands was taken into consideration, and a binary matrix was obtained. The matrix elaborated utilizing the multivariate analysis program NTSYS-pc [16]. The binary matrix was transformed in a similarity matrix using the Jacquard's similarity coefficient. The cluster analysis was carried out using the UPGMA (unweighted pair group means average) method.

\section{Antimicrobial assay}

Three pathogenic bacterial strains, viz. Bacillus subtilis (MTCC 441), Pseudomonas aeruginosa (MTCC 2453) and Streptococcus epidermis (MTCC 3322) were obtained from IMTECH, Chandigarh, India and cultured on sterile nutrient agar plates (HI-Media, Mumbai, India). The antimicrobial activity test was done by taking broth cultures of microbial strains after an incubation period of $18-24 \mathrm{~h}$ in absorbance values ranging between 0.125 and 0.134 at a wavelength of $625 \mathrm{~nm}$. The stock solutions of sample extracts were prepared in $10 \%$ dimethyl sulfoxide (DMSO) to make concentrations of $(1.25,2.5,5.0$ and 10.0$) \mathrm{mg} / \mathrm{ml}$ by serial dilution method. Antimicrobial activity test was done by using ofloxacin as standard antibiotic. Three bacterial strains were cultured in nutrient agar broth for $24 \mathrm{~h}$ at 37 ${ }^{\circ} \mathrm{C}$ and were then swabbed carefully on sterile Müller-Hinton agar plates. Dry sterilized Whatman filter paper No. 1 was used for the preparation of discs of diameter $6 \mathrm{~mm}$. The sterile discs after dipped at various concentrations of the extracts were placed on culture plates. After the $24 \mathrm{~h}$ of incubation at $37{ }^{\circ} \mathrm{C}$ the diameters of the inhibition zones produced by each disc were measured using the HiAntibiotic zone-scale (HiMedia, Mumbai, India). The inhibition zone having diameters of $(\leq) 10 \mathrm{~mm}$ were considered to be effective and of $(\geq) 11 \mathrm{~mm}$ were considered as the most effective concentration of the extract. The extracts were tested for their antimicrobial activity against $B$. subtilis, $P$. aeruginosa and $S$. epidermis. Different microorganisms were tested for their growth inhibition under different concentrations of extracts. Inhibition of microbial growth was determined by measurement of the diameter (clear zone) around each disc in mm. A control set of experiment was carried out with DMSO along with the solvent. The measurements of inhibition zone were recorded for each organism, and the MIC value was determined by using different dilutions of extracts.

\section{Determination of MIC}

The value of MIC was considered as the minimum concentration of the sample extract, which inhibited the growth of a particular microbe. The MIC value of the extracts of both plants belonging to different ecotypes was determined by earlier mentioned disc diffusion assay [17] and was further evaluated by serial dilution method prescribed by [18] on plant extracts to evaluate the antimicrobial activity.

\section{Statistical analysis}

The experiments were carried out in triplicates and the results were represented as their mean along with SEM values in triplicates. A comparison was also made to check the effectiveness of different plant species extracts against their antimicrobial activity.

\section{RESULTS}

\section{Morphological characteristics}

Different morphological characteristics of all the ecotypes were presented in table 1 that depicts colour variations in leaf and flowers (fig. 1-2). 


\section{Qualitative screening of phytochemicals}

The phytochemical screening showed the presence of a wide range of phyto compounds in all the ecotypes of $O$. corniculata and $O$. debilis. Secondary metabolites such as glycosides, saponins, tannins, and terpenoids were found in the methanol extracts of various ecotypes of $O$. corniculata (table 2) whereas no saponins and glycosides were found in all the ecotypes of 0 . debilis (table 3). The methanol extract of OC-Eco-1 contained more glycoside as compared to other ecotypes of $O$. corniculata which was noticed as visualization of colour intensities. The experiment showed the presence of saponin in all of $O$. corniculata (table 2). The absence of saponin was noticed in all ecotypes of 0 . debilis as confirmed by the foam test (table 2). Tannin was found to be more precipitated in the case of OD-Eco-3 which was distinguished from the methanolic extract of other ecotypes of both the plants. The amount of more terpenoid was found in the case of OC-Eco-1 as compare to other ecotypes of $O$. corniculata. Terpenoids were also recorded more in the extract of $O$. debilis (OD-Eco-3) as compare to others (table 2).

\section{TLC and HPTLC analysis}

The TLC-based chromatograms showed different bands in various ecotypes of both the sample extract under both the wavelength i.e. $254 \mathrm{~nm}$ and $366 \mathrm{~nm}$. TLC plate showed various bands in different ecotypes. OC-Eco-1 showed 14 bands whereas 11 spots were visible in OC-Eco-2 (fig. 3). OC-Eco-3 showed 13 spots and OC-Eco-4 possessed 12 spots (fig. 3). Likewise, OD-Eco-1 and OD-Eco-4 showed 14 bands whereas OD-Eco-2 showed 13 bands and OD-Eco3 maximum no. of bands i.e. 16 bands (fig. 3 ).

HPTLC showed a basic comparison of banding patterns of phytoconstituents among different ecotypes. OC-Eco-1 showed $\mathrm{R}_{\mathrm{f}}$ values from 0.1 to 0.86 whereas OC-Eco- 2 had $R_{f}$ values 0.1 to 0.87 (fig. 4). Similarly, $\mathrm{R}_{\mathrm{f}}$ values were found to be 0.01 to 0.93 in the case of OC-Eco-3 (fig. 4). OC-Eco-4 also showed $R_{f}$ values with range 0.01 to 0.96 (fig. 4). OD-Eco-3 showed a maximum range of $\mathrm{R}_{\mathrm{f}}$ values from 0.01 to 0.1 (fig. 4 ).

Table 1: Morphological characteristics of different ecotypes of $O$. corniculata and $O$. debilis

\begin{tabular}{|c|c|c|c|c|c|c|c|}
\hline Ecotypes/locations & $\begin{array}{l}\text { Alti-tude } \\
\text { (m) }\end{array}$ & $\begin{array}{l}\text { Latitude/longitude } \\
(\mathrm{cm})\end{array}$ & Leaf colour & Flower colour & $\begin{array}{l}\text { Leaf length } \\
\text { length }\end{array}$ & $\begin{array}{l}\text { Leaf width } \\
(\mathrm{cm})\end{array}$ & $\begin{array}{l}\text { Leaf } \\
\text { length/width }\end{array}$ \\
\hline \multicolumn{8}{|l|}{ Oxalis corniculata } \\
\hline OC-Eco-1 (Balasore) & 16 & $21.48^{\circ} \mathrm{N} 86.92^{\circ} \mathrm{E}$ & Purple & Deep yellow & 0.6 & 0.3 & 2.00 \\
\hline OC-Eco-2 (Bhadrak) & 13 & $21.01^{\circ} \mathrm{N} 86.62^{\circ} \mathrm{E}$ & Light green & Yellow & 0.7 & 0.4 & 1.75 \\
\hline OC-Eco-3 (Jajpur) & 18 & $20.76^{\circ} \mathrm{N} 86.17^{\circ} \mathrm{E}$ & Light green & Yellow & 0.5 & 0.2 & 2.50 \\
\hline OC-Eco-4 (Khurda) & 45 & $20.19^{\circ} \mathrm{N} 85.63^{\circ} \mathrm{E}$ & Greenish purple & Yellow & 0.6 & 0.3 & 2.00 \\
\hline \multicolumn{8}{|l|}{ Oxalis debilis } \\
\hline OD-Eco-1 (Balasore) & 16 & $21.48^{\circ} \mathrm{N} 86.92^{\circ} \mathrm{E}$ & Green purple & Light & 1.3 & 1.6 & 0.81 \\
\hline OD-Eco-2 (Bhadrak) & 13 & $21.01^{\circ} \mathrm{N} 86.62^{\circ} \mathrm{E}$ & Green & Purple & 1.0 & 1.5 & 0.66 \\
\hline OD-Eco-3 (Jajpur) & 18 & $20.76^{\circ} \mathrm{N} 86.17^{\circ} \mathrm{E}$ & Olive green & Pinkish purple & 1.1 & 1.4 & 0.78 \\
\hline OD-Eco-4 Khurdha) & 45 & $20.19^{\circ} \mathrm{N} 85.63^{\circ} \mathrm{E}$ & Light green & Pinkish purple & 1.5 & 2.0 & 0.75 \\
\hline
\end{tabular}

OC-Eco=Ecotype of 0 . corniculata, OD-Eco=Ecotype of $O$. debilis

Table 2: Qualitative phytochemical test for various ecotypes of $O$. corniculata and $O$. debilis

\begin{tabular}{|c|c|c|c|c|c|c|}
\hline Phytochemical & Reagents & Observation & Eco-1 & Eco-2 & Eco-3 & Eco-4 \\
\hline \multicolumn{7}{|c|}{ Oxalis corniculata } \\
\hline Saponin & Foam test & Presence of foam & +++ & +++ & ++ & +++ \\
\hline Glycoside & Kller-killiani test & Appearance ofred colour & ++ & ++ & ++ & ++ \\
\hline Terpenoid & Chloroform $+\mathrm{H}_{2} \mathrm{SO}_{4}$ & Appearance reddishbrown colour & ++ & + & + & + \\
\hline Tannin & Lead acetate test & Presence of precipitate & ++ & + & + & \\
\hline \multicolumn{7}{|l|}{ Oxalis debilis } \\
\hline Saponin & Foam test & Presence of foam & - & - & - & - \\
\hline Glycoside & Kller-killiani test & Appearance of red colour & - & - & - & - \\
\hline Terpenoid & Chloroform $+\mathrm{H}_{2} \mathrm{SO}_{4}$ & Appearance reddishbrown colour & + & + & ++ & + \\
\hline Tannin & Lead acetate test & Presence of precipitates & + & + & ++ & + \\
\hline
\end{tabular}

$+=$ present,-= absent; OC-Eco=ecotype of $O$. corniculata, OD-Eco=ecotype of $O$. debilis

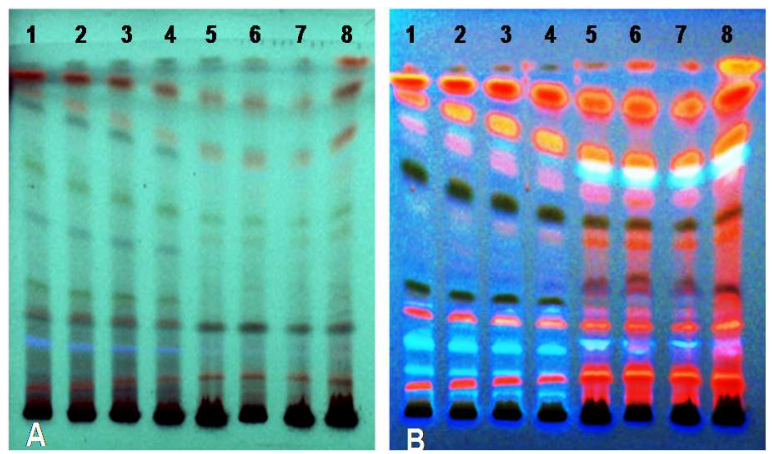

Fig. 3: TLC plate showing phytoconstituents of four ecotypes of $O$. corniculata (lanes 1-4) and $O$. debilis (lanes $5-8$ ) respectively at $254 \mathrm{~nm} \mathrm{(A)} \mathrm{and} \mathrm{at} 366 \mathrm{~nm}(B)$. Lane $1=0 C-E c o-1$, lane $2=0 C$ Eco-2, lane 3= OC-Eco-3, lane 4 = OC-Eco-4, lane 5= OD-Eco-1, lane $6=$ OD-Eco-2, lane $7=$ OD-Eco-3, lane $8=$ OD-Eco-4

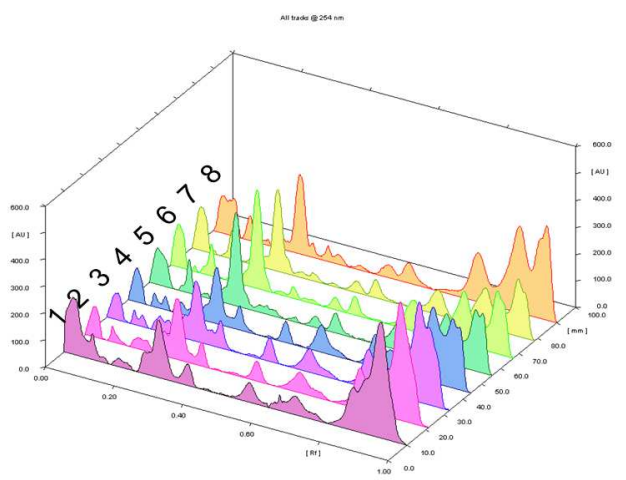

Fig. 4: HPTLC scan four ecotypes of $O$. corniculata (lanes 1-4) and 0 . debilis (lanes 5-8). Lane 1=OC-Eco-1, lane $2=0$-Eco-2, lane 3= OC-Eco-3, lane 4= OC-Eco-4, lane 5= OD-Eco-1, lane $6=$ OD-Eco-2, lane $7=$ OD-Eco-3, lane $8=$ OD-Eco-4 


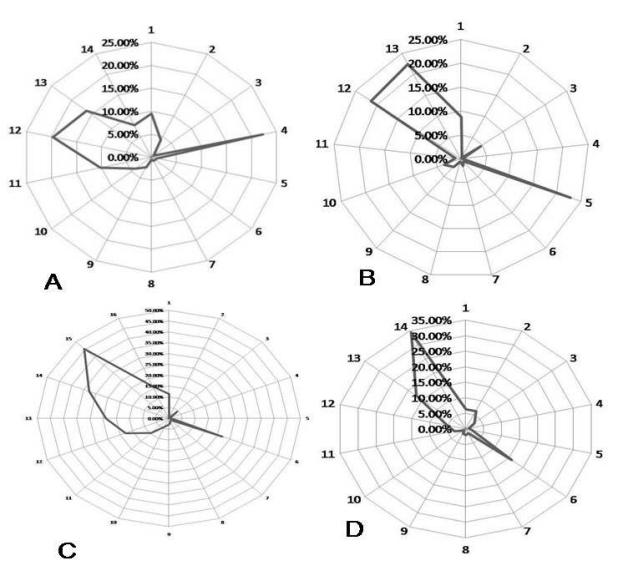

Fig. 5: Radar diagrams showing variations among ecotypes of $O$. corniculata on the basis of $R_{f}$ values of the phytoconstituents. A):

OC-Eco-1, B): OC-Eco-2, C): OC-Eco-3, D): OC-Eco-4. OC-Eco = ecotype of $O$. corniculata

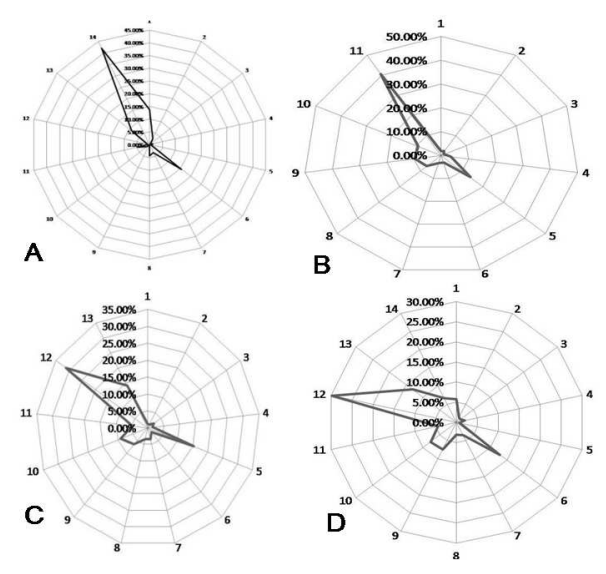

Fig. 6: Radar diagrams showing variations among ecotypes of $O$. debilis on the basis of $R f$ values of the phytoconstituents. A): OCEco-1, B): OC-Eco-2, C): OC-Eco-3, D): OC-Eco-4. OC-Eco = ecotype of o. debilis

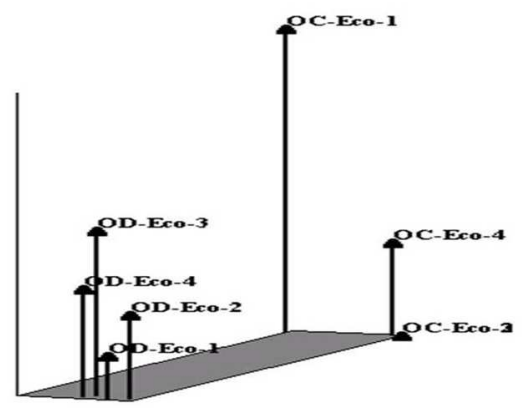

Fig. 7: Cluster analysis of genetic diversity on the basis of HPTLC banding patterns among ecotypes of $O$. corniculata and $O$. debilis OC-Eco= ecotype of $O$. corniculata and OD-Eco=ecotype of $O$. debilis

\section{Radar diagram analysis}

Fig. 5 and 6 depicted radar plots of various TLC bands with their $R f$ values. It was revealed that the qualitative and quantitative variations of different phytoconstituents reflected in the graph pattern. Significant plot shapes were noted among ecotypes of $O$. corniculata whereas in 0 . debilis Ecotype-1 found distinct from the rest three ecotypes. The quantity variation of some constituents was very prominent among the ecotypes of 0 . corniculata out of which OC-Eco-3 was quite different from the other.

\section{UPGMA analysis}

Cluster diagram showed (dis) similarity of banding patterns with respect to phytochemicals (fig. 7). The cluster analysis signified the similarity between extract of OC-Eco-2 and OC-Eco-3 having correlation coefficient 1 as shown in table 3. OC-Eco-2, OC-Eco-3, and OC-Eco-4 were included under one cluster except for OC-Eco-1 (fig. 5). In the case of $O$. debilis, the first cluster included OD-Eco-1 and OD-Eco-2 whereas the second cluster contained OD-Eco-3. The result revealed close affinity among OD-Eco-1 and OD-Eco-2. Similarly, there was a very strong similarity between OC-Eco- 2 and OC-Eco-3.

\section{Assessment of antimicrobial activity}

Leaf extracts of various ecotypes of $O$. corniculata and $O$. debilis showed various inhibition zones against three microbes i.e. $B$. subtilis, P. aeruginosa and S. epidermis (fig. 11).

Table 3: Correlation coefficient relation between ecotypes of $O$. corniculata and $O$. debilis

\begin{tabular}{|c|c|c|c|c|c|c|c|}
\hline & OC-1 & OC-2 & OC-3 & OC-4 & OD-1 & OD-2 & OD-3 \\
\hline OC-2 & 0.667 & & & & & & \\
\hline OC-3 & 0.667 & 1.000 & & & & & \\
\hline OC-4 & 0.750 & 0.889 & 0.889 & & & & \\
\hline OD-1 & 0.395 & 0.577 & 0.517 & 0.543 & & & \\
\hline OD-2 & 0.447 & 0.593 & 0.593 & 0.533 & 0.895 & & \\
\hline OD-3 & 0.474 & 0.517 & 0.517 & 0.516 & 0.762 & 0.857 & \\
\hline OD-4 & 0.421 & 0.500 & 0.500 & 0.552 & 0.842 & 0.762 & 0.727 \\
\hline
\end{tabular}

$\mathrm{OC}=$ ecotype of $O$. corniculata and $\mathrm{OD}=$ ecotype of $O$. debilis.

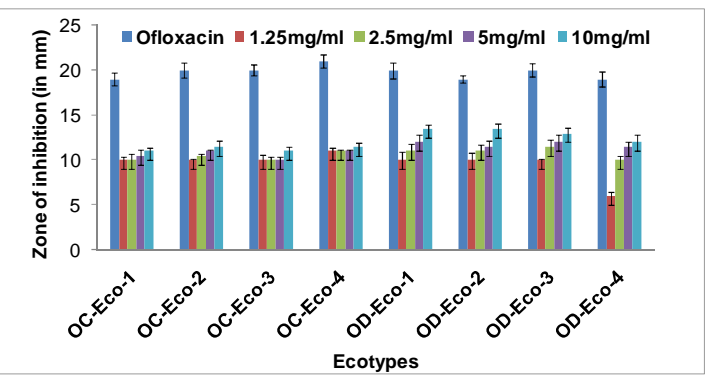

Fig. 8: Comparative analysis of the antimicrobial effect of phytoconstituents on B. Subtilis. OC-Eco=ecotype of $O$. corniculata and OD-Eco=ecotype of $O$. debilis
Maximum growth inhibition activity against $B$. subtilis (inhibition zone $=14 \mathrm{~mm}$ ) followed by OD-Eco-2 (inhibition zone $=13 \mathrm{~mm}$ ), OD-Eco-4 (inhibition zone $=12.5 \mathrm{~mm}$ ) and OD-Eco-1 (inhibition zone $=12 \mathrm{~mm}$ ) (fig. 8). Ecotypes of both plants showed no significant antimicrobial activity against $P$. aeruginosa (fig. 9). Still ecotypes of O. debilis showed signified inhibition zone as compared to ecotypes of 0 . corniculata. OD-Eco-3 extract showed

maximum antimicrobial activity against $P$. aeruginosa at $10 \mathrm{mg} / \mathrm{ml}$ exhibiting inhibition zone $10.8 \mathrm{~mm}$ which was more as compare to the antibiotic i. e Ofloxacin (inhibition zone $=8 \mathrm{~mm}$ ) (fig. 9).

Extract of ecotypes of $O$. corniculata viz. OC-Eco-1, OC-Eco-2, OCEco-3 and OC-Eco-4 exhibited significant role in inhibiting the $S$. epidermis at $10 \mathrm{mg} / \mathrm{ml}$ of inhibition zone near about $20 \mathrm{~mm}$ (fig. 10). However, OC-Eco-4 showed the inhibition zone $20 \mathrm{~mm}$ against the 
above said bacterium at $10 \mathrm{mg} / \mathrm{ml}$ (fig. 10). Antimicrobial activity assay of an extract of all ecotypes of $O$. debilis exhibited less zone of inhibition against $S$. epidermis. The methanol extract of OD-Eco-3 showed a maximum zone of inhibition $(14.0 \mathrm{~mm})$ against $S$. epidermis whereas OD-Eco-4 showed inhibition zone of $13.5 \mathrm{~mm}$.

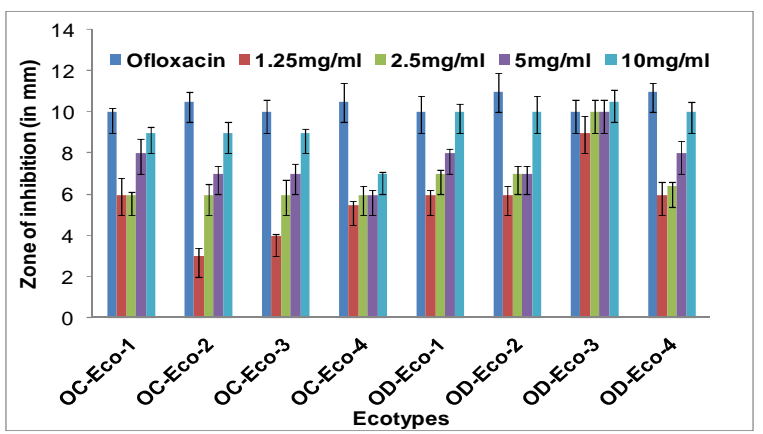

Fig. 9: Comparative analysis of the antimicrobial effect of phytoconstituents on P. aeruginosa. OC-Eco=ecotype of $O$. corniculata and OD-Eco=ecotype of $O$. debilis

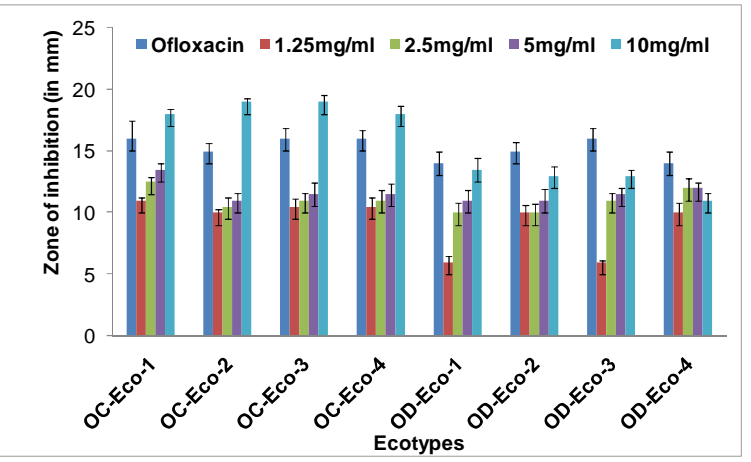

Fig. 10: Comparative analysis of the antimicrobial effect of phytoconstituents on $S$. epidermis. OC-Eco=ecotype of $O$. corniculata and OD-Eco=ecotype of $O$. debilis
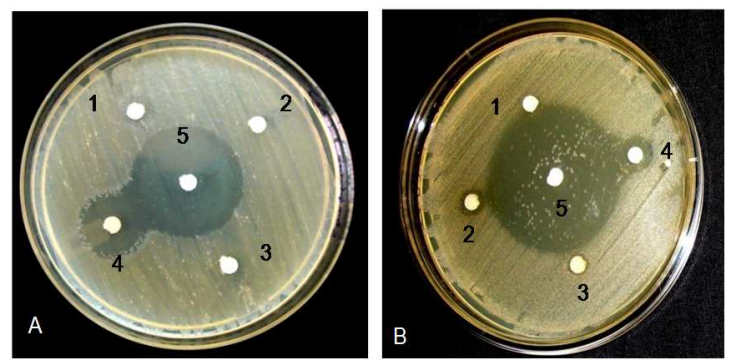

Fig. 11: Antimicrobial activity of OC-Eco-1 and OD-Eco-3 against microbes; A) S. epidermis B) B. subtilis showing maximum zone of inhibitions. $1=1.25 \mathrm{mg} / \mathrm{ml}, 2=2.5 \mathrm{mg} / \mathrm{ml}, 3=5.0 \mathrm{mg} / \mathrm{ml}$,

$4=10.0 \mathrm{mg} / \mathrm{ml}$ crude extract, $5=1.25 \mathrm{mg} / \mathrm{ml}$ ofloxacin. $0 C$ Eco=ecotype of $O$. corniculata and OD-Eco=ecotype of $O$. debilis

\section{DISCUSSION}

The wild medicinal plants must be documented for their widespread application as consumed orally. So, the phytochemical investigations must be done along with the biological screening, to know the therapeutic dynamics of medicinal plants. Phytochemical analysis of methanol extracts of different ecotypes of $O$. corniculata and $O$. debilis showed the presence of various phytoconstituents (tables 2 and 3). Extract of OC-Eco-1 showed more concentration of glycoside, tannin and terpenoids as compared to other ecotypes of $O$. corniculata (table 2). Reports revealed that the methanolic and ethanolic extract of $O$. corniculata showed the presence of carbohydrate, glycosides, flavonoids, phenolic compounds, protein (12.5\%), amino acids and volatile oil [19]. O. debilis (OD-Eco-3) showed the highest terpenoid and tannin content as compared to other ecotypes of $O$. corniculata. There was no indication of glycosides and saponin in the case of methanolic extracts of ecotypes of $O$. debilis. Hence, there was a great variation among the ecotypes of $O$. corniculata and 0 . debilis. The differences of the phytochemical composition are not only depending on solvents but also include edaphic and climatic conditions of the plant [20]. TLC was done for identification of different components in the extracts (fig. 3). The chromatographic analysis of samples using TLC was performed to separate and identify the single or mixture of constituents in each extract.

HPTLC was scanned at $254 \mathrm{~nm}$ and $366 \mathrm{~nm}$ to find the minimum number of components and peak area. The fingerprint of methanol extract of OC-Eco-1 showed 14 spots in the solvent system having different Rf values followed by OC-Eco-2 (12 spots) and OC-Eco-3 (14 spots), OC-Eco-4 (13 spots) (fig. 4). Likewise, HPTLC chromatograms of methanol extract of OD-Eco-3 showed 14 spots followed by 13 spots in case of OD-Eco-4. A total of 13 spots were noted down in case of ODEco-2, whereas 14 spots were noticed in the case of OD-Eco-1 (fig. 4,). HPTLC fingerprint is a versatile tool for qualitative and quantitative analysis of active phytoconstituents. HPTLC paved the way for selection of extracts which helped in isolating different constituents and studying their pharmacological activity.

The study demonstrated the presence of genetic differentiation in the populations into four ecotypes. In the present study 2 major clusters were formed on the basis of a phytochemical profile in HPTLC. Cluster-I represents the ecotypes of 0 . corniculata with the very close relationship among OC-Eco-2 and OC-Eco-3 which were collected from Bhadrak and Jajpur districts respectively (fig. 7). The dendrogram also revealed that OC-Eco-4 had less genetic distance from OC-Eco-2 and OC-Eco-3. But OC-Eco-1 showed more dissimilarity in genetic constituents than the other ecotypes of $O$. corniculata. Cluster II comprised of OD-Eco-1 of Balasore, OD-Eco-2 of Bhadrak, OD-Eco-3 of Jaipur and OD-Eco-4 of Khurda district (fig. 7). The cluster analysis showed that OD-Eco-1 and OD-Eco-2 possessed the close genetic affinity. But comparing them OD-Eco-3 and OD-Eco-4 were distantly related (table 3). It is hypothesized that the different clusters may be different in physiology or chemistry, or the differences may be as a result of complex interactions of climatic or edaphic factors. They may be different in ploidy levels or the groups may be different cytotypes.

The anti-microbial activity assay showed the potentiality of methanol extract of ecotypes of both plants, i.e., $O$. corniculata and $O$. debilis. The methanol extract of OC-Eco-4 was more effective against S. epidermis with an inhibition zone of $19.5 \mathrm{~mm}$ (fig. 10), and ODEco-3 was most effective against $B$. subtilis with an inhibition zone of $11.00 \mathrm{~mm}$ as compared to another extract (fig. 8). This signified the efficacy of methanol extract of OD-Eco-3 against the microbes which might be due to the presence of tannins. These secondary metabolites play a significant role in inhibiting the growth of human pathogens and act against them developing effective defense mechanism [21]. Oxalis debilis Ecotype-3 (OD-Eco-3) contained more tannin and it formed the irreversible complexes with proline-rich compounds (table 3). These compounds actively inhibited the cell protein synthesis and stopped microbial growth. The methanol leaf extracts of $A$. altilis against various human pathogens was effective due to the presence of wide range of phytoconstituents especially tannins [4]. Tannin inhibited the proteolytic enzymes secreted by the microbes. Methanol extracts of all ecotypes of 0 . corniculata possess glycoside and saponin whereas no glycoside in the case of methanolic extracts of 0 . debilis ecotypes (tables 2 and 3). The glycoside got hydrolysed to release phenolic compounds which are toxic to microbes [22]. The result also signified that all ecotypes of both the plants were not that much effective against $P$. aeruginos $a$ as compared to other microbes (fig. 9). Extracts of ecotypes of $O$. corniculata were most effective against $S$. epidermis as compared to ecotypes of $O$. debilis (fig. 10). The present study is the first kind of report on the medicinally important plant $O$. debilis basing on its antimicrobial activity. In this study, the methanol extract of $O$. debilis 
ecotypes showed immense importance as compared to ecotypes of $O$. corniculata. This report not only provides an insight of ecotype study on the basis of phytoconstituent analysis and antimicrobial activity of methanolic extract of different ecotypes of both $O$. corniculata and $O$. debilis, but also conferred the value in disclosing the new source of economical materials as tannins, saponins, oils, gums, flavonoids for the synthesis of chemical substances.

\section{CONCLUSION}

The present study is a comprehensive evaluation of the selected samples. It incorporates pharmacognostic and antimicrobial investigations along with the analysis of phenotypic variation, and genetic diversity of different accessions of various ecotypes of above-said plants belong to family Oxalidaceae. Phytochemical and genetic variation occurred among the ecotypes of both plants. Saponin was absent almost in all ecotypes of 0 . debilis. The investigations revealed that the ecotypes of both plants under study showed high antimicrobial activity. The present study, therefore, underlines the importance of complete exploitation of the potency of the plant $O$. debilis in the field of medicine and chemical industry.

\section{ACKNOWLEDGEMENT}

The authors are thankful to P. G Department, Utkal University for providing infrastructural facilities to carry out the research. The research funding supported by DRS-III, UGC, and DST-FIST Govt. of India are highly acknowledged.

\section{CONFLICT OF INTERESTS}

\section{Declared none}

\section{REFERENCES}

1. Pradhan C, Mohanty M, Rout A, Das AB, Satapathy KB, Patra HK. Phytoconstituent screening and comparative assessment of antimicrobial potentiality of Artocarpus altilis fruit extracts. Int J Pharm Pharm Sci 2013;5:840-3.

2. Cragg GM, Newman DJ, Sander KM. Natural products in drug discovery and development. J Nat Prod 1997;60:52-60.

3. Goyal BR, Goyal RK, Mehta AA. Phytopharmacognosy of Archyranthes aspera: a review. Pharmacogn Rev 2008;1:143-50.

4. Pradhan C, Mohanty M, Rout A. Phytochemical screening and comparative bio-efficacy assessment of Artocarpus altilis leaf extracts for antimicrobial activity. Front Life Sci 2013;6:71-6.

5. Kirtikar, Basu. Indian medicinal plants. MS periodical experts. $3^{\text {rd }}$ Ed. New Delhi; 1975. p. 1-437.

6. Kumar A, Niketa, Rani S, Sagwal S. An absolute review on Oxalis corniculata Linn. Int J Res Pharm Biomed Sci 2012;3:1173-88.
7. Kumar A, Chaudhary P, Verma KN, Kumar P, Lalit. TLC based phytochemical and antioxidant analysis of Oxalis corniculata L. Int Res J Pharm Appl Sci 2013;3:6-12.

8. Ramappa R, Mahadevan GD. In vitro antimicrobial activity of various plant latex against resistant human pathogens. Int J Pharm Pharm Sci 2011;3:70-2.

9. Sarma A, Sarmah P, Dolai DK, Medhi P. Oxalis debilis var. corymbosa (DC.) Lourteig and Oxalis corniculata L. a comparative study of nutraceutical properties. Int J Curr Res 2015;7:11307-10.

10. Denton MF. A monograph of Oxalis, section Ionoxalis (Oxalidaceae) in North America. Publication of the Michigan State University Museum, Biological Series 1973;4:455-615.

11. Lourteig A. Oxalis L. subgenera Monoxalis (Small) Lourt. Oxalis trifidus Lourt. Bradea 2000;7:201-629.

12. Haines HH. The botany of Bihar and Orissa. Adlard and Son and West Newman Ltd; 1988. p. 156-1237.

13. Evans WC. An index of medicinal plants. A Textbook of Pharmacognosy. 14 ${ }^{\text {th }}$ Ed; 1997; 7:12-4.

14. Kokate CK. Plant constituents in Practical Pharmacognosy; 2001. p. 107-10.

15. Mace Gorbach SL. Anaerobic bacteriology for clinical laboratories. Pharmacognosy 1963;23:89-91.

16. Rohlf FJ. Ntsys-PC. Numerical taxonomy and multivariate analysis system Version 1. 80-Setauket, NY, Exeter Software; 1993.

17. Bauer AW, Perry DM, Kirby WMM. Single disc antibiotic sensitivity testing of Staphylococci. AMA Arch Intern Med 1959;104:208-16.

18. Prescott LM, Harley JP, Klein DA. Microbiology. 6th ed. New York: McGraw-Hill Publishers; 2005. p. 782-86.

19. Raghavendra MP, Satish S, Raveesha KA. Phytochemical analysis and antibacterial activity of Oxalis corniculata; a known medicinal plant. My Sci 2006;1:72-8.

20. Pradeepa M, Kalidas V, Geetha N. Qualitative and quantitative phytochemical analysis and bactericidal activity of pelargonium graveolens L'HER. Int J Appl Pharm 2016;8:7-11.

21. Daferera DJ, Ziogas BN, Polissiou MG. The effectiveness of plant essential oils in the growth of Botrytis cinerea, Fusarium sp. and Clavibacter michiganensis subsp. michiganensis. Crop Prot 2003;22:39-44.

22. Aboaba 00, Efuwape BM. Antibacterial properties of some Nigerian species. Biol Res Commum 2001;13:183-8.

\section{How to cite this article}

- $\quad$ Eleena Panda, Chinmay Pradhan, Anath Bandhu Das. Variations in phytoconstituents and antimicrobial activities in ecotypes of Oxalis corniculata L. and Oxalis debilis kunth. Int J Pharm Pharm Sci 2016;8(10):270-275. 